\title{
Ontogeny of Brain Nuclei Controlling Song Learning and Behavior in Zebra Finches ${ }^{1}$
}

\author{
SARAH W. BOTTJER, ${ }^{2}$ SHERRI L. GLAESSNER, AND ARTHUR P. ARNOLD \\ Department of Psychology, University of California, Los Angeles, Los Angeles, California 90024
}

\begin{abstract}
An anatomically discrete system of interconnected brain nuclei controls production of learned song patterns in adult male zebra finches (Poephila guttata). The corresponding nuclei in females, who do not sing, are greatly reduced in volume. Cells in some telencephalic song-control nuclei accumulate androgens, and male nuclei contain a much higher proportion of hormone-concentrating cells than do female nuclei. The main purpose of this experiment was to examine the normal ontogeny of the total volume of various telencephalic nuclei that have been directly or indirectly implicated in song learning and behavior in male zebra finches. In addition, the corresponding nuclei of age-matched females were examined.
\end{abstract}

The major findings were as follows: the volumes of the caudal nucleus of the ventral hyperstriatum (HVc), the robust nucleus of the archistriatum (RA), and area $X$ increased sharply in males between 12 and 53 days of age, whereas brain regions not involved with song control increased much less. Increases in the size of HVc occurred prior to those in RA and area $X$. Previous studies have shown that males are learning the auditory and motor characteristics of song during this time. In contrast, the volume of the magnocellular nucleus of the anterior neostriatum (MAN) decreased precipitously in males between 25 and 53 days. Measurements of neuron density and soma size demonstrated that this decreased volume is attributable to a loss of greater than $50 \%$ of the neurons in MAN. We have previously shown that lesions of MAN during this time completely disrupt song development. The volumes of HVc and RA were smaller in iemales than in males at all ages studied. Between 12 and 25 days the volumes of female HVc and RA increased less than brain regions not involved with song control. Female HVc and RA decreased slightly in volume between 25 and 53 days.

These findings suggest the following: (1) the sexual dimorphism in the song-control system is evident at 12 days but increases markedly thereafter, primarily due to the growth of male HVc and RA; (2) the increase in volume in male HVc leads that in RA and area $X$, suggesting that hormones may act directly on HVc to trigger growth, and that HVc may then exert a trophic influence on RA and area $X$;

Received July 18, 1984; Revised October 3, 1984;

Accepted October 8, 1984

${ }^{1}$ We wish to thank Lis Miesner, Arl Woudward, Sue Eirıslein, Kathy Nordeen, and Sheila Smith for assistance with various aspects of this project. This work was supported by United States Public Health Service Grants NS18392 to S. W. B. and NS19645 to A.P. A.

${ }^{2}$ To whom correspondence should be addressed. and (3) MAN is large when birds are learning to produce song and decreases markedly in size around the time when the motor pattern of song begins to stabilize. The loss of neurons from MAN may be attributable to cell death or reditferentiation and migration of some neurons.

Song behavior is a sexually dimorphic activity in many species of passerine birds. Males learn to produce a species-typical song during a so-called "critical" or sensitive period of development, whereas females sing very little or not at all (e.g., see Bottjer and Arnold, 1985, for a review). In zebra finches (Poephila guttata), juvenile males must hear the song they will subsequently produce up until approximately 35 to 40 days of age (Immelmann, 1969). Zebra finches learn to produce a song pattern which is the same as, or very similar to, that of their fathers. Juvenile males first begin to produce song-type vocalizations themselves around 25 days of age. These initial vocalizations are referred to as "subsong," and are extremely variable. The temporal order of song syllables becomes stereotyped between 50 and 60 days, and the variability in the form of individual syllables also decreases greatly. After this phase, production of individual song syllables is perfected (i.e., becomes highly stereotyped), and the overall pattern of song only changes in terms of a faster tempo (Arnold, 1975a).

Even though zebra finch song appears highly stereotyped in terms of syllable morphology and sequence by approximately 75 days of age, deafening birds up to 85 days of age produces profound disruption of the song pattern (Price, 1979; S. W. Bottjer, unpublished observations). Zebra finches are considered to be adult by approximately 90 days of age, and deafening birds after this age has little or no effect on song production (Price, 1979; Bottjer and Arnold, 1984). At this juncture, the song is said to be "crystallized." The song patterns of adult males usually contain approximately tive or six syllables that are often highly frequency modulated and may contain many harmonics. These song patterns remain highly stereotyped and do not change throughout adulthood. In contrast to males, female zebra finches never sing, even when they are administered testosterone in adulthood.

Neural control of song is vested in an interconnected system of anatomically discrete brain nuclei (Fig. 1). Neurons in the robust nucleus of the archistriatum (RA) and the caudal nucleus of the ventral hyperstriatum $(\mathrm{HVC})$ are directly and indirectly connected, respeclively, with the motor neurons that innervate the vocal organ (the tracheosyringeal portion of the hypoglossal nucleus (nXIlts)). Neurons of the magnocellular nucleus of the anterior neostriatum (MAN) project monosynaptically to both HVC and RA (Nottebohm et al., 1982). Area $X$ is a large nucleus in the parolfactory lobe that receives a projection from $\mathrm{HVC}$. Little is known of its function, although Nottebohm et al. (1976) showed that unilateral lesion of area $X$ has no effect on song production in adult male canaries. It is (tentatively) included as part of the song-control system because it receives a major projection from HVc. Lesions in HVc or RA com- 


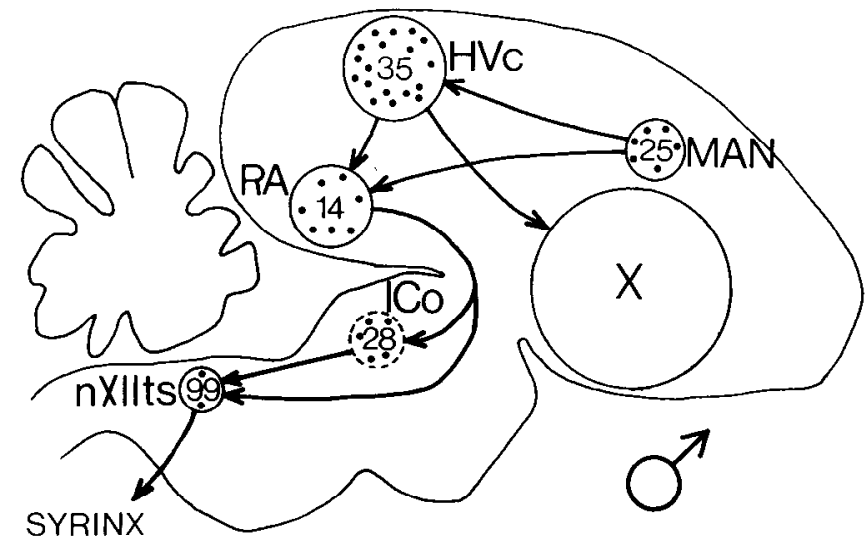

Figure 1. A schematic diagram depicting a sagittal view of the major nuclei constituting the song-control system in adult male zebra finches. Neurons in HVc project directly onto neurons in RA. RA neurons project to IXIIIs; these hypoglossal motor neurons innervate the vocal organ (syrinx) RA also projects to the intercollicular nucleus (ICO). MAN and area $X(X)$ are two forebrain nuclei that are monosynaptically connected with $\mathrm{HVC}$ and/or RA. Dots indicate nuclei contaıning androgen-accumulating cells; numbers are percentages of cells labeled within a given nucleus. See the text for additional details. This figure is based on data from Nottebohm et al. (1976, 1982), Arnold and Saltiel (1979), and Arnold (1980b).

pletcly disrupt song production in adult male songbirds (Nottebohm et al., 1976). Lesions of MAN disrupt song development in juvenile zebra finches but have no effect on adult song behavior (Bottjer et al., 1984).

This neural system is also sexually dimorphic. The volume of songcontrol nuclei in males can be up to 5 times greater than that of corresponding nuclei in females (Nottebohm and Arnold, 1976), and soma size, number, and dendritic arbor of neurons in RA are significantly greater in males than in females (DeVoogd and Nottebohm, 1981; Gurney, 1981). In addition, cells in many song-control nuclei concentrate androgens (Fig. 1), and there is a striking sex difference in terms of such androgen accumulation-HVc and MAN of adult male zebra finches have a much higher proportion of androgen-concentrating cells than do those of adult females (Arnold and Saltiel, 1979; Arnold, 1980a). Song production in adult male zebra finches is androgen dependent: castration reduces both the rate of singing and the tempo of song (Prove, 1974; Arnold, 1975b). Thus, both song behavior and its neural and hormonal bases are highly sexually dimorphic in adult zebra finches.

Investigations of the song-control system have been largely confined to examination of brain structures in adult birds. Very little is known about the normal development of song nuclei in young birds. However, description of the normative events in the ontogeny of the song system would greatly facilitate the development of hypotheses concerning neural mechanisms of song learning. Therefore, the purpose of this experiment was to begin to describe the normal ontogeny of the neural network that controls song learning and behavior in zebra finches. We began by measuring the total volume of various song-control nuclei in male zebra finches at different stages of song development. In addition, the corresponding nuclei of age-matched females were examined. By comparing changes in the volume of male song-control nuclei with changes in song behavior, and by comparing relative changes in male versus female nuclear volume, we hoped to generate specific hypotheses as to some of the neuronal events underlying the development of vocal behavior in males, as well as the sexual dimorphisms between adult males and females.

\section{Materials and Methods}

All zebra finches used in this study were hatched in our breeding colony. Eighteen males and 12 females ranging in age from 11 to 57 days were overdosed with anesthetic (Equithesin) and perfused with saline and buffered formalin. The brains were removed immediately and postfixed in formalin for at least 1 week. They werc subscquently embcddcd in gelatin-albumin, frozen-sectioned in the transverse plane at $25 \mu \mathrm{m}$, and stained with thionin. Alternate sections were examined at $\times 46$ magnification using a microprojector, and the nuclei HVc, RA, MAN, area $X, n X \mid l t s$, and nucleus rotundus (Rt) were traced in males. The first five nuclei have been directly or indirectly implicated in the control of song behavior (see above). Rt, a thalamic nucleus not known to be involved with song control, was included as a control measure in order to determine whether changes in the volume of brain regions were restricted to the song system. $R t$ is involved with processing of visual information; this nucleus receives a large projection from the optic tectum and, in turn, projects to a restricted area of the ipsilateral telencephalon (the ectostriatum; see Cohen and Karten, 1974). As an additional control, the average cross-sectional area of the telencephalon (Tel) at the level of the anterior commissure was measured. The corresponding regions were traced in females, with two exceptions: area $X$ cannot be seen in Nisslstained female zebra finch brains, and the borders of MAN were too diffuse to be traced reliably. The total area of each region that was traced was calculated with the aid of a digitizing tablet interfaced with a microcomputer. Reconstruction of the total volume of a given brain region was obtained by summing the areas of that region from all sections traced, dividing this value by the square of the magnification factor, and multiplying by the sampling interval $(0.05 \mathrm{~mm})$. Neither the age nor the sex of any animal was known by the experimenters at the time the brain areas were traced or the resultant data entered into the computer.

All brains were divided into three age groups with means of 12 (range $=$ 11 to 13 ; males, $n=5$; females, $n=3$ ), 25 (range $=23$ to 29 ; males, $n=$ 7; females, $n=5$ ), and 53 (range $=50$ to 57 ; males, $n=6$; females, $n=4$ ) days. These three ages correspond to the time (a) before production of any song by males, $(b)$ when song sounds are first produced, and $(c)$ when the final song pattern begins to stabilize. Female zebra finches do not sing at any age.

\section{Results}

The mean volume of each of the brain regions measurcd and the ratios of 25- to 12-day volumes and 53- to 25-day volumes are given in Table I. Because there were no systematic differences between the left and right volumes of any nucleus measured, volume reconstructions correspond to the summed values of the two sides.

The volumes of HVC and RA were smaller in females than in males at all ages studied, whereas there were no sex differences in the volumes of Tel and Rt. Thus, the sex difference in volumes of songcontrol nuclei seen in adult birds is evident at 12 days of age and increases thereafter (Table I). The ratio of male to female $\mathrm{HVC}$ increased from 1.92 to 3.85 and 6.20 at 12,25 , and 53 days, respectively; the corresponding ratios for $\mathrm{RA}$ were $1.46,1.85$, and 5.74. The increasing difference in volume between male and female song-control nuclei is due primarily to a steady increase in size of male song nuclei during development, and also to a decrease in the size of corresponding nuclei in females between 25 and 53 days.

A statistical analysis of the data was performed as follows. A fourway analysis of variance utilized sex and age as between-group factors and region type (song versus nonsong) and specific region (RA, HVc, Rt, Tel) as within-group factors; specific region was nested within region type (i.e., song regions = RA, HVC; nonsong regions $=\mathrm{Rt}, \mathrm{Tel})$. This analysis yielded a highly significant interaction of sex $\times$ age $\times$ region type $(F(2,24)=10.99, p=0.0006)$. Planned comparisons were performed to determine whether song regions ( $R A$ and $H V c$ ) were significantly different between males and females at each of the ages studied; the sex difference was not significant at 12 days $(F(1,24)=2.78, p=0.10)$ but was highly significant at 25 and 53 days $(F(1,24)=43.34, p=0.00001$ and $F(1,24)=$ $128.17, p<0.00001$, respectively).

The major findings among females were as follows. Between 12 and 25 days the volumes of female HVc and RA increased by $23 \%$ and $15 \%$, respectively, but Tel increased by $32 \%$ and Rt increased by $18 \%$ (Table I). The volume of $\mathrm{nXllts}$ almost doubled in size. The volumes of female I IVc and RA decreased by $21 \%$ and $43 \%$, respectively, between 25 and 53 days, and $n X$ Xlls decreased by $27 \%$. In contrast, Tel did not change during this time, although the volume on Rt decreased by $15 \%$. 
TABLE ।

Volumes $\pm S D$ of various brain regions in 12-, 25-, and 53-day males and females

\begin{tabular}{|c|c|c|c|c|c|c|}
\hline & Region & Day 12 & Day 25 & Day 53 & Day $25 / 12^{a}$ & Day $53 / 25^{a}$ \\
\hline \multirow[t]{7}{*}{ Males } & HVc & $0.165 \pm 0.057$ & $0.408 \pm 0.085$ & $0.521 \pm 0.124$ & 2.47 & 1.27 \\
\hline & $\mathrm{RA}$ & $0.155 \pm 0.022$ & $0.226 \pm 0.028$ & $0.402 \pm 0.101$ & 1.46 & 1.78 \\
\hline & Area X & & $1.536 \pm 0.331$ & $2.262 \pm 0.475$ & & 1.47 \\
\hline & MAN & & $0.565 \pm 0.153$ & $0.247 \pm 0.050$ & & 0.44 \\
\hline & nXllts & $0.074 \pm 0.008$ & $0.109 \pm 0.017$ & $0.123 \pm 0.024$ & 1.47 & 1.13 \\
\hline & $\mathrm{Rl}$ & $1.098 \pm 0.133$ & $1.166 \pm 0.111$ & $0.980 \pm 0.166$ & 1.06 & 0.84 \\
\hline & Tel & $0.910 \pm 0.055$ & $1.151 \pm 0.085$ & $1.119 \pm 0.134$ & 1.26 & 0.97 \\
\hline \multirow[t]{5}{*}{ Females } & $H V_{C}$ & $0.086 \pm 0.018$ & $0.106 \pm 0.034$ & $0.084 \pm 0.036$ & 1.23 & 0.79 \\
\hline & $\mathrm{RA}$ & $0.106 \pm 0.022$ & $0.122 \pm 0.033$ & $0.070 \pm 0.024$ & 1.15 & 0.57 \\
\hline & $\mathrm{nX}$ Xlts & $0.052 \pm 0.005$ & $0.100 \pm 0.022$ & $0.073 \pm 0.005$ & 1.92 & 0.73 \\
\hline & $\mathrm{Ht}$ & $1.046 \pm 0.128$ & $1.231 \pm 0.274$ & $1.049 \pm 0.23 b$ & 1.18 & 0.85 \\
\hline & Tel & $0.878 \pm 0.074$ & $1.159 \pm 0.111$ & $1.172 \pm 0.115$ & 1.32 & 1.01 \\
\hline
\end{tabular}

${ }^{a}$ These columns represent the corresponding ratios for each area between 25- and 12-day birds, and 53- and 25-day birds, respectively.

Planned comparisons constituting part of the main statistical analysis (see above) revealed a significant interaction of age $\times$ region type for females $(F(2,24)=5.19, p=0.01)$. However, this interaction was attributable to the fact that non-song areas (Rt and Tel) increased significantly more than song areas (RA and HVc) between 12 and 25 days $(F(1,24)=10.05, p=0.004)$. There was no difference in the degree of change between song and non-song regions between 25 and 53 days $(F<1)$; thus, the decrease in volume of female RA and HVc between 25 and 53 days was not significant.

Among males, the volumes of HVC and RA increased by $147 \%$ and $46 \%$, respectively, between 12 and 25 days, whereas Tel and Rt increased by only $26 \%$ and $6 \%$, respectively (Table I). The volume of $n X I l t s$ increased by $47 \%$. Between 25 and 53 days, male, HVc and RA increased by $27 \%$ and $78 \%$, respectively, whereas Tel and $R t$ decreased by $3 \%$ and $16 \%$. Area $X$ could not be seen in three of five 12-day males and was well defined enough to be traced in only one of the remaining two males (the volume of area $X$ for this one bird was $0.829 \mathrm{~mm}^{3}$ ). By 25 days area $X$ had attained a large volume, which continued to increase (by $47 \%$ ) between 25 and 53 days. MAN could be seen in all 12-day males, but its borders were too diffuse to be traced reliably; the volume of MAN at this age lies somewhere between 0.20 and $0.38 \mathrm{~mm}^{3}$. The most striking finding of the experiment was that MAN in males had a large volume at 25 days, which decreased by $59 \%$ between 25 and 53 days. This result was so unexpected that a second, independent observer traced MAN in 25- and 53-day males (the sex but not the age of these birds was known to the observer). This second reconstruction of the volume of MAN vielded values of $0.638 \pm 0.088$ and $0.259 \pm$ 0.065 (means \pm SD) in 25- and 53-day males, respectively. These mean values are $13 \%$ and $5 \%$ greater than the respective values obtained by the first observer. The greater difference between observers for the 25-day birds reflects the fact that the borders of MAN were slightly difficult to discern even at this age. The important point remains, however, that both observers judged MAN to be more than twice as large at 25 days as at 53 days. A graphic comparison of the volume changes in male HVc, RA, and MAN is shown in Figure 2.

Planned comparisons were performed to determine whether the volume increases in male song regions (RA and HVc) were significantly greater than the increases in non-song regions (Rt and Tel) across the three ages measured. There was a highly significant interaction of age $\times$ region type $(F(2,24)=15.10, p=0.0002)$, indicating that the volume of song regions increased significantly more than that of non-song regions. An additional planned comparison revealed that there was also a significant $\mathrm{RA} \times \mathrm{HV}_{\mathrm{c}}$ interaction $(F(2,24)=7.74, p=0.003)$, reflecting the fact that HVc volume increased more steeply than RA volume between 12 and 25 days in males, whereas the converse was true between 25 and 53 days.

Another analysis of variance was performed using area $X$ and

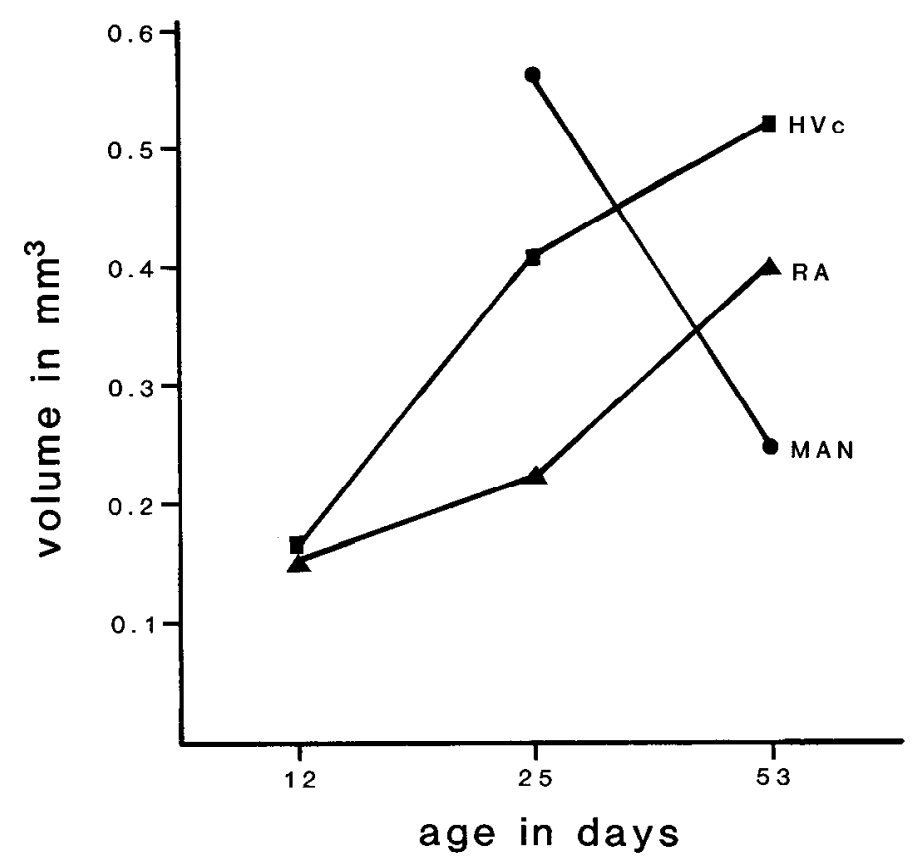

Figure 2. A graphic description of the volume changes in $H V c, R A$, and MAN during development in juvenile males. The volume of MAN cannot be measured reliably in 12-day males. See the text for additional details.

MAN as song regions and Rt and Tel as non-song regions; only data from 25- and 53-day males were available because MAN and area $X$ couid not be measured in females or 12-day males (see above). Planned comparisons revealed significant age $\times$ region interactions for both area $X$ and MAN with non-song regions $(F$ $(1,11)=19.15, p=0.0014$, and $F(1,11)=9.75, p=0.0095$, respectively). The former interaction indicates that the volume of area $X$ was increasing relative to non-song regions, and the latter indicates that the volume of MAN was decreasing relative to nonsong regions.

The decrease in volume of MAN between 25 and 53 days was particularly interesting to us, because this interval corresponds to a restricted period of development when lesions of MAN disrupt song learning (Bottjer el al., 1984). Lesions in MAN lose their effectiveness between 50 and 60 days of age, as the motor pattern of song is established (i.e., as the temporal order of notes stabilizes). In order to determine whether the decreased volume of MAN could be accounted for by a decrease in number of neurons, we measured the somal area and density of neurons in MAN of each of the 25and 53-day males. The sections were viewed at a final magnification of $\times 1000$, and somas were traced with the aid of a camera lucida. Totals of 435 and 414 neurons were traced in the 25- and 53-day 
groups, respectively (range $=52$ to 82 cells for individual birds) . Neurons were easily distinguishable from glial cells in MAN because they contained large, pale nuclei with one or two round, darkly staining nucleoli. Glial cells had very poorly defined nuclei with several small, irregularly sized nucleoli. There was no difference in mean somal area of neurons between the two groups (Table II), or in the distribution of soma size (Fig. 3). The distributions in Figure 3 indicate that there are two classes of neurons in MAN as defined by soma size; the first peak occurs between 60 and $90 \mu \mathrm{m}^{2}$ and the second peak occurs around $210 \mu \mathrm{m}^{2}$.

Neuronal density was measured with the aid of a $0.01-\mathrm{mm}^{2}$ ocular grid; the number of ncurons in which the nucleolus fell within the grid was counted in 10 separate locations throughout MAN for each bird. There was no difference in neuronal density between the two groups (Table II), although the older birds tended to have slightly higher densities. The total number of neurons in MAN was estimated using our measurements of total volume of the nucleus and neuronal density (Table II); these data indicate a loss of more than $50 \%$ of the neurons in MAN during this period. Figure 4 shows the crosssectional area of MAN for one male from each age group.

\section{Discussion}

Several intriguing results have been revealed by examining the normal developmental course of the neural network that controls vocal behavior in zebra finches. These results have implications for mechanisms of both song learning and sexual differentiation of the brain. As regards song learning, we have seen that brain nuclei directly involved in song production by adult birds, such as HVC and

TABLE ॥

Somal area, density, and estimated number of neurons in MAN of 25- and 53 day malcs (moan $\pm S D$ )

\begin{tabular}{cccc}
\hline Age & Somal Area & Neuron Density & Neuron Number \\
\hline & $\mu m^{2}$ & $\mu m^{3}\left(10^{3}\right)$ \\
25 days & $161.70 \pm 73.90$ & $0.070093 \pm 0.002551$ & 39,603 \\
53 days & $159.84 \pm 70.57$ & $0.077853 \pm 0.010196$ & 19,230 \\
\hline
\end{tabular}

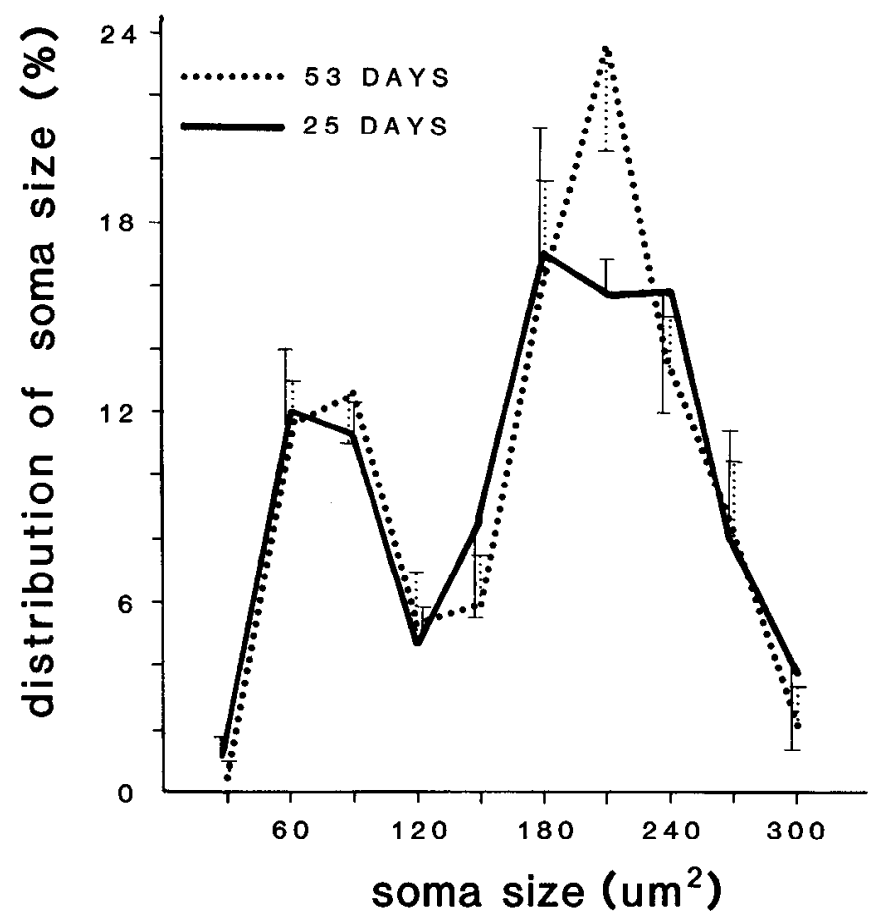

Figure 3. The distribution of soma size of individual neurons in MAN for 53- and 25-day old males. Values plotted are mean percentage of cells within a given size class \pm SE. Cell size is plotted along the abscissa as bins of $30 \mu \mathrm{m}^{2}$ width.
$\mathrm{RA}$, are increasing dramatically in size prior to and during the initial period of song production. Both HVc and RA increase substantially in size between 12 and 25 days (the latter age being the time when incipient song sounds are first produced), whereas brain regions not known to be involved with song control exhibit much more modest increases. HVc and RA continue to increase in size up until approximtely 53 days, which is around the time when the motor pattern of song begins to stabilize, whereas non-song regions show no change in size or slight decreases during this time. Comparison of our results with those oblained by Arnold (1980b) and Nottebohm and Arnold (1976) suggests that the volumes of HVc, RA, and area X in our 53day birds are comparable to their adult values. We report a slightly larger value for MAN in 53-day males than the adult value of Arnold (1980); this difference may reflect the hazards of inter-experiment comparisons, or may indicate that MAN decreases somewhat in size after 53 days.

Nottebohm (1980, pp. 108-110) discussed unpublished data showing that HVC and RA grow very rapidly during the period of subsong in juvenile male canaries. The volume of HVc was still only $50 \%$ of its adult value when subsong ended, but the rate of growth slowed down thereafter. It would be interesting to know how the later stages of growth in canary HVc and RA correlate with plastic song (a phase that lasts for several months in canarics) and song crystallization.

We do not know whether experiential factors contribute to these volume increases. For example, the experience of hearing a song model early in development could contribute to volume changes in $H V_{c}$, particularly since some HVc neurons have been shown to respond to playback of conspecific song (McCasland and Konishi, 1981; Margoliash, 1983). Similarly, the experience of producing incipient song vocalizations (with resultant auditory and perhaps proprioceptive feedback) might also produce neuronal changes that contribute to volume increases in central song nuclei. The normative volume changes we have described here will serve as an important foundation for future experiments in which the influence of various experiential factors can be explicitly tested and compared to the normal ontogeny of the song-control system.

The most exciting finding (to us) is that MAN is large when birds are first learning to produce song and decreases markedly in sice by the time that the motor pattern of song begins to stabilize. The decrease in volume of MAN also correlates with the time period when lesions of MAN disrupt song development-that is, MAN lesions become largely ineffective between 50 and 60 days, when the motor pattern of song becomes fairly stereotyped (Bottjer et al., 1984; Bottjer and Arnold, 1985). We have seen that this decrease in size is attributable to a loss of more than $50 \%$ of the neurons in MAN between 25 and 53 days (Table II). One possible interpretation of this remarkable pattern of findings is that MAN subserves some important (as yet unidentified) function for vocal learning early in song development; we have suggested elsewhere that MAN neurons may help to mediate motor learning or auditory-motor integration of the song pattern (Bottjer et al., 1984). If so, it may be that neurons are lost from MAN as the motor pattern of song develops-perhaps neurons involved with control of "erroneous" sounds that are not included in the final song pattern are not retained in MAN. As the motor pattern of song stabilizes, MAN lesions become ineffective in disrupting song development and the volume of MAN would presumably approach its adult value (cell loss would be curtailed). After this time, the function of MAN is no longer important for song learning to proceed, and/or functions important for song learning are shifted to other areas of the brain (such as $\mathrm{HV} c$ ?). Of course, the validity of these ideas remains to be subjected to experimental test. ${ }^{3}$

\footnotetext{
${ }^{3}$ We do not know, for example, whether the number of syllables produced by juvenile zebra finches decreases as song development proceeds and MAN decreases in neuron number. However, Marler and Peters (1982a, b) have demonstrated a marked attrition in the number of syllables produced by swamp sparrows (Melospiza georgiana) as their song patterns become stereotyped. It therefore seems possible that a similar pattern may be seen during the development of zebra finch song.
} 


\section{5-DAY MALE}

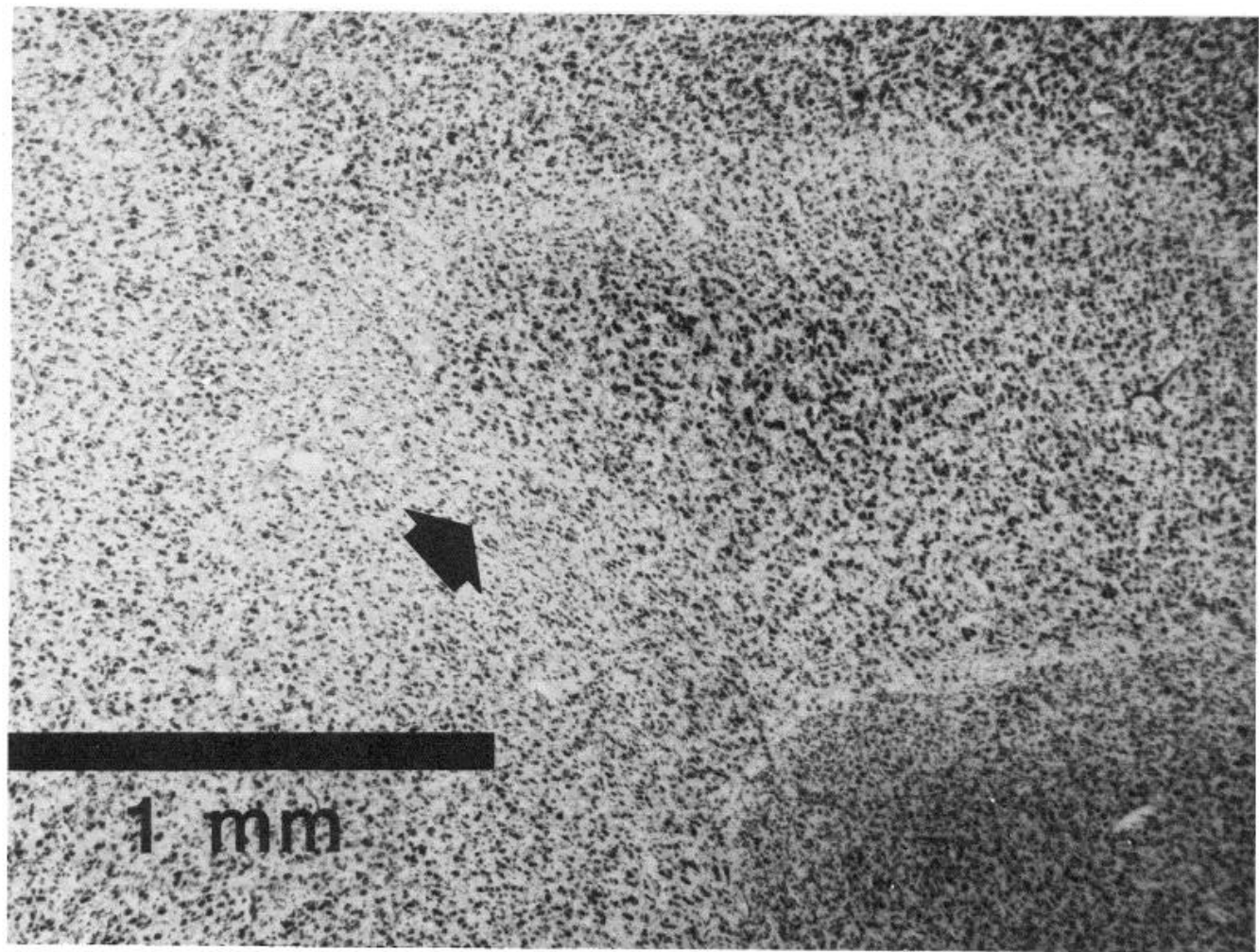

\section{3-DAY MALE}

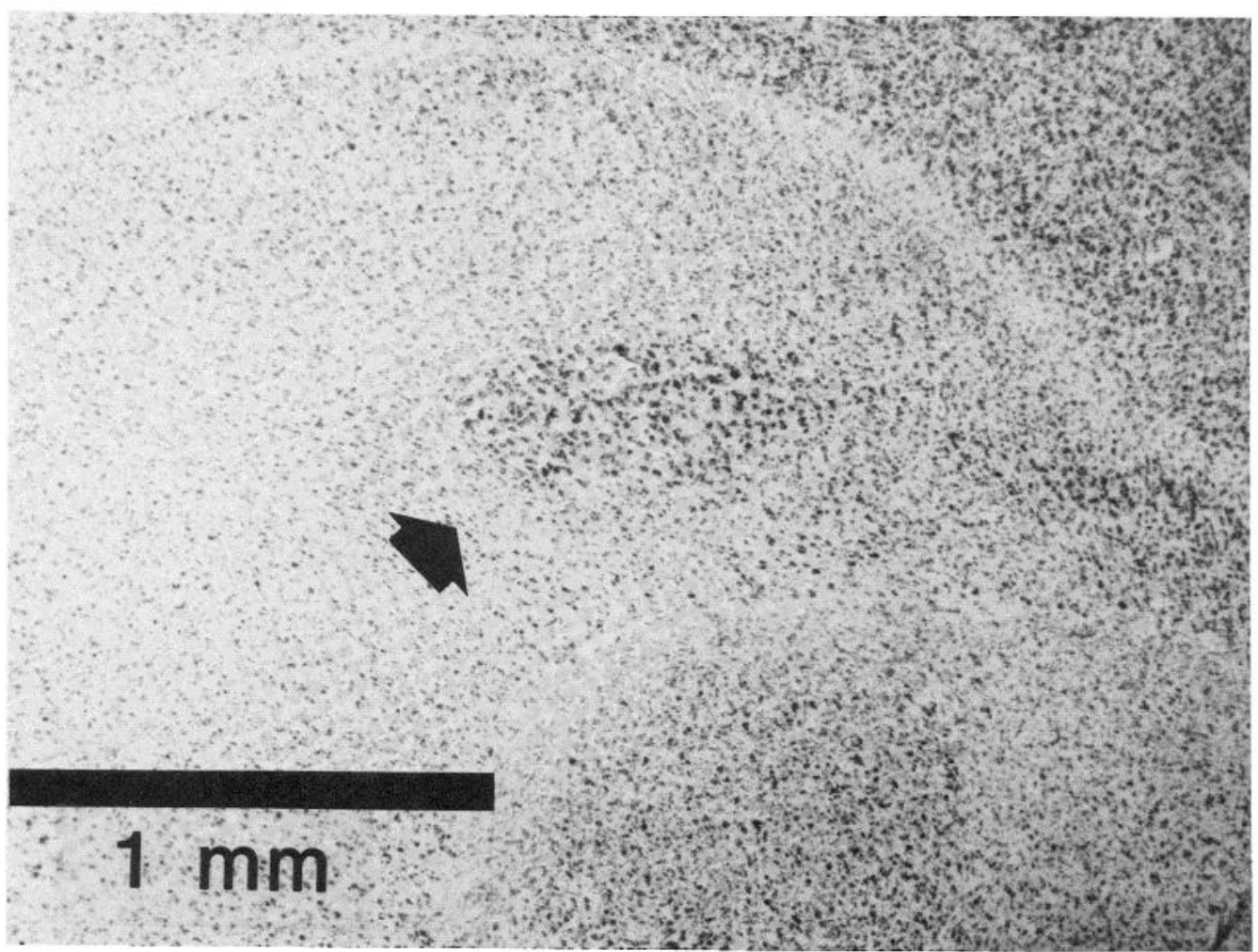

Figure 4. This photomicrograph shows transverse sections through MAN for one male from each of the 25- and 53-day groups. Arrows indicate location of MAN. 
We do not know the mechanism of cell loss from MAN, but two alternatives suggest themselves. One explanation is that there is massive neuronal death in MAN. This alternative seems exciting, since neuronal death is normally a feature of embryonic or early postnatal development and has never been studied in relation to the development of a learned behavior (see Oppenheim, 1981). An alternative mechanism would be for some MAN neurons to redifferentiate. That is, some neurons within MAN may change their morphology, their histochemical characteristics, and their function. This latter hypothesis requires that such cells migrate outside the borders of MAN, or that only cells in the periphery of MAN undergo such a change, leaving a "core" of neurons that we see as MAN in older birds. This outcome also seems unprecedented. Either way, elucidation of the relationship between cell loss from MAN and song development may greatly increase our understanding of the mechanisms of vocal learning.

As regards sexual differentiation, we have seen that there is aiready a small difference in the volume of HVc and RA between males and females at 12 days of age (one that is approaching statistical significance). This finding concurs with the work of Gurney and Konishi (1980; Gurney, 1981, 1982; Konishi and Gurney, 1982) in suggesting that hormones act very early in life (prior to 12 days) to initiate changes leading to sex differences in brain structures of zebra finches. They showed that neonatal administration of estrogen to female zebra finch chicks was particularly effective in masculinizing the volume of song-control nuclei-that is, the volumes of HVc and RA in adult females that had received estrogen at the time of hatching were significantly larger than those of normal females. Administration of testosterone or dihydrotestosterone to such estrogenized females in adulthood induced further increases in nuclear volume as well as the development of song behavior.

After 12 days, the volumes of male HVc and RA show significant increases up until 53 days that are specific to the song system. In contrast, female HVc and RA actually increase less in volume than do non-song control regions between 12 and 25 days, and they decrease in size between 25 and 53 days, during which time Tel does not change (however, this decrease was not statistically significant). The increase in volume seen in male song-control nuclei may be accounted for by increases in neuronal soma size or dendrilic arbor, decreases in cell density, and/or an increase in number of cells. Correspondingly, the slight atrophy of female HVc and RA may be attributable to decreases in cell size and number, and increases in cell density. The mechanism responsible for such atrophy is unknown.

It is tempting to speculate that the relative paucity of androgenaccumulating cells seen in adult female HVC and RA is causally related to the decrease in volume (or the absence of an increase) observed during the development of these nuclei. Nordeen et al. (1984) have recently demonstrated that estrogen treatment of female zebra finch chicks greatly increases the proportion of hormoneaccumulating cells seen in HVc and MAN of these birds as adults. We also know from the work of Gurney and Konishi (1980) that such estrogen treatment acts to increase the volume of song-control nuclei (see above). Further study of the exact mechanism whereby estrogen influences the development of cells that accumulate androgens in adulthood, as well as the relationship between hormone accumulation and neural development of song-control nuclei, will greatly increase our understanding of sexual differentiation of the song system.

One particularly interesting aspect of our results is that the increase in volume in male HVc appears to lead that in RA: HVc increased much more steeply in size than RA between 12 and 25 days, whereas RA increased in size more sharply than $\mathrm{HVc}$ between 25 and 53 days. In adult male zebra finches, HVc contains a higher proportion of androgen-accumulating cells than does RA, and androgen-labeled cells are not seen in area X (Arnold, 1980a). This pattern of findings may suggest that hormones act directly in HVC to trigger growth, and that HVc may induce secondary growth in monosynaptically connected nuclei via some trophic influence. This idea is supported by the fact that the 12-day male with the largesl $H V c$ also had the largest and most well defined area $X$ (see above) and the next to largest RA. Such a "domino" theory of sexual differentiation of the brain has been discussed by Arnold (1980a; cf. Arnold and Gorski, 1984). That is, steroids may act directly to promote neuronal growth in hormone-sensitive areas such as HVC and MAN; this enhanced growth could then induce greater growth and synaptogenesis in regions that receive projections from $H V_{C}$ and MAN, such as RA and area $X$. Our initial results, described herein, are quite consistent with such a hypothesis.

\section{References}

Arnold, A. P. (1975a) The effects of castration on song development in zebra finches. J. Exp. Zool. 191: 261-278.

Arnold, A. P. (1975b) The effects of castration and androgen replacement on song, courtship, and aggression in zebra finches (Poephila guttata). J. Exp. Zool. 191: 309-326.

Arnold, A. P. (1980a) Quantitative analysis of sex differences in hormone accumulation in the zebra finch brain: Methodological and theoretical issues. J. Comp. Neurol. 189: 421-436.

Arnold, A. P. (1980b) Effects of androgens on volumes of sexually dimorphic brain regions in the zebra finch. Brain Res. 185: 441-444.

Arnold, A. P., and R. A. Gorski (1984) Gonadal steroid induction of structural sex differences in the central nervous system. Annu. Rev. Neurosci. 7: 413-442.

Arnold, A. P., and A. Saltiel (1979) Sexual difference in pattern of hormone accumulation in the brain of a songbird. Science 205: 702-705.

Bottjer, S. W. and A. P. Arnold (1984) The role of feedback from the vocal organ. I. Maintenance of stereotypical vocalizations by adult zebra finches. J. Neurosci. 4: 2387-2396

Bottjer, S. W., and A. P. Arnold (1985) The ontogeny of vocal learning in songbirds. In Developmental Processes in Psychobiology and Neurobiology, E. Blass, ed., Plenum Press, in press.

Bottjer, S. W., E. Miesner, and A. P. Arnold (1984) Forebrain lesions disrupt development but not maintenance of song in passerine birds. Science 224: 901-903.

Cohen, D. H., and H. J. Karten (1974) The structural organization of avian brain: An overview. In Birds: Brain and Behavior, I. J. Goodman and M. W. Schein, eds., pp. 29-73, Academic Press, Inc., New York.

DeVoogd, T. J., and F. Nottebohm (1981) Sex differences in dendritic morphology of a song control nucleus in the canary: A quantitative Golgi study. J. Comp. Neurol. 196: 309-316.

Gurney, M. E. (1981) Hormonal control of cell form and number in the zebra finch song system. J. Neurosci. 1: 658-673.

Gurney, M. E. (1982) Behavioral correlates of sexual differentiation in the zebra finch song system. Brain Res. 231: 153-172.

Gurney, M. E., and M. Konishi (1980) Hormone-induced sexual differentiation of brain and behavior in zebra finches. Science 208: 1380-1382.

Immelmann, K. (1969) Song development in the zebra finch and other estrildid finches. In Bird Vocalizations, R. A. Hinde, ed., pp. 61-74, Cambridge University Press, New York.

Konishi, M., and M. E. Gurney (1982) Sexual differentiation of brain and behavior. Trends Neurosci. s: 20-23.

Margoliash, D. (1983) Acoustic parameters underlying the responses of song-specific neurons in the white-crowned sparrow. J. Neurosci. 3: 10391057.

Marler, P., and S. Peters (1982a) Developmental overproduction and selective attrition: New processes in the epigenesis of bird song. Dev. Psychobiol. 15: 369-378.

Marler, P., and S. Peters (1982b) Subsong and plastic song: Their role in the vocal learning process. In Acoustic Communication in Birds, D. E. Kroodsma and E. H. Miller, eds., Vol. 2, pp. 25-50, Academic Press, Inc. New York.

McCasland, J. S., and M. Konishi (1981) Interaction between auditory and motor activities in an avian song control nucleus. Proc. Natl. Acad. Sci. U. S. A. 78: 7815-7819.

Nordeen, K. W., E. J. Nordeen, and A. P. Arnold (1984) Estrogen masculinizes the pattern of androgen accumulation in the brain of a songbird. Soc. Neurosci. Abstr. 10: 454

Nottebohm, F. (1980) Brain pathways for vocal learning in birds: A review of the first ten years. Prog. Psychobiol. Physiol. Psychol. 9: 85-124.

Nottebohm, F., and A. P. Arnold (1976) Sexual dimorphism in vocal control areas of the songbird brain. Science 194: 211-213. 
Nottebohm, F., T. M. Stokes, and C. M. Leonard (1976) Central control of song in the canary (Serinus canarius). J. Comp. Neurol. 165: 457-468.

Nottebohm, F., D. B. Kelley, and J. A. Paton (1982) Connections of vocal control nuclei in the canary telencephalon. J. Comp. Neurol. 207: 344357.

Oppenheim, R. W. (1981) Neuronal cell death and some related regressive phenomena during neurogenesis: A selective historical review and progress report. In Studies in Developmental Neurobiology: Essays in Honor of Viktor Hamburger, W. M. Cowan, ed., pp. 74-133, Oxford University Press, New York.

Price, P. H. (1979) Developmental determinants of structure in zebra finch song. J. Comp. Physiol. Psychol. 93: 260-277.

Prove, E. (1974) Der Einfluss von Kastration und Testosteronsubstitution auf das Sexualverhalten mannlicher Zebrafinken (Taeniopygia castanotis Gould). J. Ornithol. 115: 338-347. 